\section{Ciudades: vistas y color. El caso de El Cerro Rico en Potosí}

La experiencia de color que aquí reflejamos se ha realizado en 150 viviendas con alto valor patrimonial en el Centro Histórico de Potosi (Bolivia). Previamente se ha atendido a necesidades de saneamiento básico como la provisión de agua potable y alcantarillado, baños y cocinas, ampliación o recuperación de espacios que superen el hacinamiento de la familia, o reparando techos, pisos o enlucidos, a la vez que solucionando problemas de humedades, falta de iluminación, ventilación y soleamiento. Entre todos los edificios intervenidos destaca el Pabellón de los Oficiales Reales. Todo el trabajo se complementó con la recuperación de la imagen urbana de más de 250 fachadas en las calles más representativas de la ciudad, dentro del Programa de Cooperación de la Consejería de Obras Públicas y Transportes de la Junta de Andalucía con el municipio de Potosí, con apoyo del Programa de Patrimonio para el Desarrollo de la Agencia Española de Cooperación Internacional y Desarrollo.

En el caso de Potosí el uso de óxidos férricos del Cerro Rico, la altísima concentración del pigmento mineral que tienen, frente a la intensidad de los rayos ultra violeta a cuatro mil metros de altura, hace que sean mucho más directos en su difracción que a nivel del mar. Las experiencias realizadas durante más de quince años demuestran que los pigmentos aplicados a las fachadas de los monumentos y viviendas de Potosí ya descritos no han perdido su coloración en lo más mínimo y, al contrario, la aplicación de colores industriales, por más finos que fueren, en dos años, han perdido su coloración en cerca de un $50 \%$ y en pocos años más están totalmente descoloridos.

Como la ciudad se encuentra a una altura media de 4000 metros y tiene una insolación muy fuerte durante varias horas en torno al mediodía y, por otra parte, puede llegarse al congelamiento al amanecer, se ha experimentado lo suficiente como para afirmar que este revoque de color debe hacerse en base a cal grasa muy bien apagada durante meses, la cual debe combinarse con arena gruesa de río bien lavada en una proporción de 1 de cal y 4 de arena, y debiendo hacerse esta mezcla unos días antes de su aplicación sobre el paramento de adobe, removiendo la mezcla diariamente. Con esta mezcla se realiza el revoque grueso. Con similares dosis se procede con el revoque fino, aunque usando arena fina en lugar de gruesa y el añadido a la mezcla -muy importante- del pigmento de óxidos férricos elegido - procedente de El Cerro -, una vez que el mismo ha sido tamizado.

En cuanto a los aglutinantes existe una gran variedad, pudiendo ser de origen animal, vegetal o sintético. Entre los de origen animal -usado en nuestra experiencia-, se encuentran las colas, que se extraen de las reses, peces, conejos, cerdos y otros animales. También ha sido común el uso de la caseína extraída de la leche.

Para evitar el desprendimiento del color se le puede aplicar encima de la pintura una especie de barniz final-dos manos de movilith o carpicola diluida en agua al $3 \%$ en una primera mano y al $7 \%$ en una segunda mano-, lo que evitará que se manche una persona que se apoye o que la lluvia arrastre pintura.

Es importante mencionar que un consolidante o endurecedor que le da gran resistencia e impermeabilidad al revoque de cal y a las pinturas naturales es el hidróxido de bario, que en una adición del $1 \%$ al $2 \%$ a la mezcla o la pintura nos brinda excelentes resultados.

Entre los aglutinantes de origen vegetal el más utilizado tradicionalmente en Potosí es el jugo de cactus, una especie de goma, conocida como mucílago, que se obtiene al diluir en agua fría. Su calidad depende del tipo de cactus.

En la Rehabilitación del Pabellón de los Oficiales Reales se han fabricado in situ las piezas de adobe - secadas al sol -, de los muros que se han reconstruido. Sobre ellos se ha aplicado encima este revoque, coloreando el edificio en rojo por su exterior, y en color amarillento el patio. Todos los pigmentos utilizados pertenecen al Cerro Rico, excepto el añil de la portada interior que se llevó desde Sevilla.
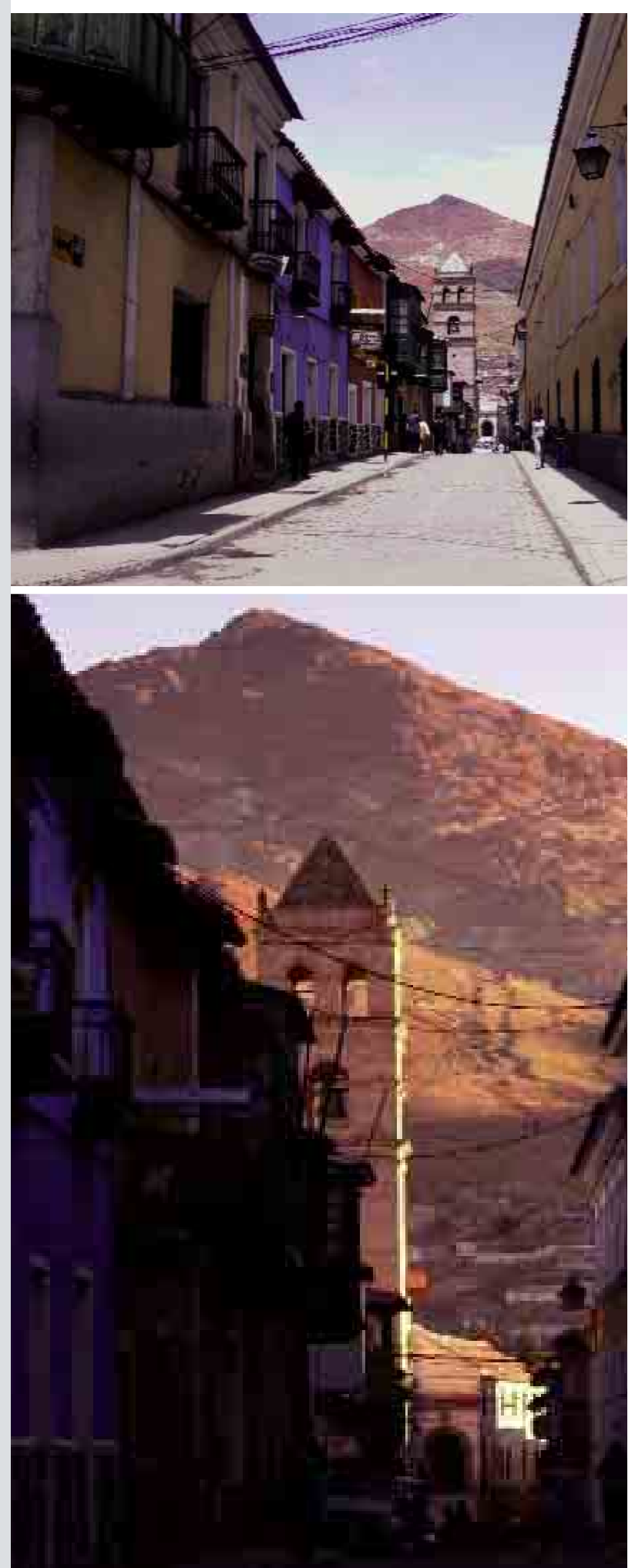